\title{
Teaching about Dementia in School Children
}

\author{
Krishna Prasad Pathak ${ }^{1 *}$ and Tara Gaire ${ }^{2}$ \\ ${ }^{1}$ Assistant Professor, Nepal Open University, Nepal \\ ${ }^{2} \mathrm{MScN}$, Innovative Health Science College, Kathmandu \\ *Corresponding Author: Krishna Prasad Pathak, Assistant Professor, Nepal Open University, Nepal.
}

Received: June 18, 2019; Published: July 04, 2019

DOI: $10.31080 /$ ASMS.2019.03.0345

Worldwide dementia seems significant burden issue to handle for health professionals, family members, caregivers and patients [1]. Typically, we associate dementia with older age and we do not consider that how does dementia affect children. However, it may appear with the younger age people Dementia fact sheet [2]. A bunch of overlapping sign and symptoms that may have overlapping sign and symptomps may appear associated with inherited disorders may appear with the children and that may lead brain disorders. Also, some more leading causes like; the lipids, cholesterol accumulate, liver and spleen dysfunction can result confusion. Likewise, fail in the exam, learning difficulties with their study, mood disorder, difficulty to identify the daily activities, difficulty reasoning to answer and write, low level of brain activities in the class rooms or with the per groups, less activeness with other participants in the school age group children [3]. However, yet, no gold standard diagnostics guidelines. It is fact that a special approach is essentials to get help for understanding of dementia to the school children. Unfortunately, we do not consider this issues neither in instructions nor health care settings.

Study indicates that the following factors are highly associated to have dementia related issues with the children; for instance; Adrenoleukodystrophy, Subacute-sclerosing Panencephalitis (SSPE), Tay Sachs disease, Canavan disease, Alexander disease, Autism (Infantile), Batten disease, Metabolic diseases, Niemann-Pick Type C, Juvenile Huntington's diseaseetc [4]. Children show some similar symptoms as adults have as mentioned above characteristics like; fear, anger, irritation, impatience, and less 'acceptable', feel grief and sadness, emotions.

Thus, some ways may help to talk with the kids about dementia and dementia affected persons and about their rest of life with the dementia: it may worthy to talk the truth of dementia facts and its adverse consequences and impacts, children may misunderstood that the demented patients lost all their life but better to remind the children that the patients are still a person they can do as like previous they did, he/she can work as like others without any barriers, demented persons are not a mad or useless person they can share their experiences of their life that may have fruitful for the youngers who are in stages of life carers. Additionally, make the preparations to the children with the unexpected result with the loved one, get involved such brain activities (puzzle game, quiz context, cross matching, social involvement/participation/) and many more exercise with them, emphasise with the positivity and share with the children. Try to elaborate the neurodegenerative disease and its disorders in the brain mean that the patients will not be able to manage the behavioural activities-it is the result of disease but not intentional, laughing is a kind of relief, it helps but never think it might be humor [5-8].

Children may feel, share, and adjustment about the disease in the future. Therefore, there is a need to implement in the system school children in dementia that help $t$ minimise the contradictions regarding dementia issues. All the above mentioned facts and figures draws the attention that an educational intervention program to the children are essential to make a clear understanding of way to take further actions about the disease management.

In school, the health educators can take effective roles to minimise dementia and deal with the associated problem by providing educational interventions. The teaching can reduce the stigma associated with dementia, increase younger people's knowledge and understanding of the condition, and promote social inclusion.

Teaching about dementia in school children helps to improve the communication skills between the patients and children. Similarly, develops self-confidence and self-esteem of both younger and older people. Educational programme provides the opportunity to work with the aim of Every Child Matters 'Enjoy and achieve' and 'Make a positive contribution' significant outcomes. After, the children can become more tolerant of those around them and, show an positive respect towards the older people with dementia. 
Bibliography

1. Henry Brodaty. "Family care givers people with dementia". Dialogues in Clinical Neuroscience 11.2 (2009): 217-228.

2. Dementia fact sheet (2016).

3. Pathak K and Gaire T. "Do children suffer from dementia?" Science and Technology Research (2015).

4. Hempel C. "Dementia in children and teens- when kids Brains regress like the elderly". Addi and Causi fund (2010).

5. Jacklin E and Mathieson T. "Dementia in children, teenagers and young adults A guide for parents, teachers and care professionals". The Dementia Services Development Centre, Iris Murdoch Building, University of Stirling, Stirling, FK9 4LA (2009).

6. Alzheimer society UK. "Explaining dementia to children and young people" (2013).

7. Demetris J. "How to help children to understand the dementia". Alzheimer's net (2015).

8. Iliffe S and Manthorpe J. "Dementia in the community; challenges for primary care development". Clinical Gerentlogy (2002): 243-252.

\section{Volume 3 Issue 8 August 2019}

(C) All rights are reserved by Krishna Prasad Pathak and Tara Gaire. 